\title{
Obstetrical outcome of Swine flu in pregnancy at tertiary care centre of Uttarakhand
}

\author{
Namrata Saxena, Prachi Singh, Shweta Jain, Vineeta Gupta, Bhawna Sharma, Kamal S Negi, \\ Narotam Sharma, Yashika Pehal
}

\begin{abstract}
Corresponding author: Dr Prachi Singh, Assistant Professor, Department of Obstetrics and Gynaecology, Shri Guru Ram Rai Institute of Medical and Health science, Dehradun, Uttarakhand, India; Email - prachisingh221108@gmail.com
\end{abstract}

Distributed under Attribution-Non Commercial - Share Alike 4.0 International (CC BY-NC-SA 4.0)

\begin{abstract}
Objectives: The objective of this study is to assess clinical characteristics, obstetric and perinatal outcome of pregnant women with H1N1 infection. Methods: A retrospective observational study was conducted at a tertiary care teaching hospital. All clinically suspected, probable as well as confirmed cases of swine flu, in pregnancy were included. We analyzed the presenting complaints, condition on admission, criteria for admission in ICU, abnormalities in laboratory reports, course of illness and perinatal outcome. Results: A total of 52 patients in pregnancy and postpartum period were admitted with fever or acute respiratory illness over the period of two years from March 2017 to February 2019. Mean age of patients was 25.88 years. 32 patients were H1N1 positive. In which, 29 were pregnant and 3 patients were postpartum. Mean gestational age was 31 weeks. Out of 32 patients, 11 patients were admitted in intensive care unit. There were 4 deaths due to H1N1 illness and all were in $3^{\text {rd }}$ trimester. Conclusion: Acquiring infection in late trimester, late initiation of antiviral treatment and presence of co-morbid illness were high risk factors for developing critical illness. We emphasize that high index of suspicion, early diagnosis; early antiviral therapy and immunization to pregnant women are to reduce the complications, ICU admissions and mortality in this group.
\end{abstract}

Keywords: H1N1, influenza, perinatal outcome, pregnant women.

Novel H1N1 infection was discovered for the first time in human beings in April 2009. It was earlier known as "Swine Flu". 1, 2 The outbreak has since reached pandemic status. Pregnant women are at especially high risk for the development of complications of H1N1 influenza A. ${ }^{2-5}$ During pregnancy, healthy women have a 4 to 5 folds increased rate of serious illness and hospitalization with influenza. ${ }^{6}$ Therefore it becomes essential for the obstetricians to be aware of the clinical presentation as well as the management of H1N1 infection in pregnancy.

Presentation of novel H1N1 infection in pregnancy mimics that of other types of influenza infections with fever accompanying symptoms of acute respiratory tract infection. Other complaints may include headache, fatigue, body aches, vomiting, and diarrhea. Their clinical presentation can be complicated by development of a secondary bacterial infection (such as pneumonia). Symptoms commonly develop within 1 week of exposure, and patients are contagious for approximately 8 days thereafter. ${ }^{1}$ There is no evidence to suggest that pregnant women are at increased susceptibility of catching the flu virus. ${ }^{7}$ In pregnancy, there is modification of the immune system to prevent rejection of

Received: $11^{\text {th }}$ March 2020. Accepted: $12^{\text {th }}$ April 2020.

Saxena N, Singh P, Jain S, Gupta V, Sharma B, Negi KS, et all. Obstetrical outcome of Swine flu in pregnancy at tertiary care centre of Uttarakhand. The New Indian Journal of OBGYN. 2020; 7(1): 63-70. 
the fetus and placenta. It is thought that the cell mediated immunity is modified by an increased in the production of Thelper cells as opposed to T-killer cells to reduce the risk of rejection. However, due to the modification in their immune systems to accommodate their developing fetus and adaptations in their body as a result of the hormonal and physical changes, they are at greater risk of developing complications should they acquire the illness. Pregnancy per se leads to several changes in respiratory physiology. There is reduction in tidal volume and increased pulmonary congestion. In addition to these changes, with advancing pregnancy, there is compression over diaphragm which adversely affect the lung capacity. Together these changes make the woman more susceptible to develop respiratory complications in the form of pneumonitis and acute lung injury. There may also be a delay in seeking medical help because of a number of factors especially in the developing countries. Prominent among them being a lack of awareness and in some cases gender bias. These factors along with the physiological changes have an impact on outcome of H1N1 infected pregnant women in low income nations ${ }^{8}$.

There are not enough data in literature especially in developing countries to ascertain the load of illness during pregnancy. The present study was undertaken to assess clinical characteristics, obstetric and perinatal outcome of pregnant women with $\mathrm{H} 1 \mathrm{~N} 1$ infection.

\section{Materials and methods}

A retrospective observational study was conducted at the department of Obstetrics and Gynaecology, Shri Guru Ram Rai Institute of Medical and Health Science, Dehradun. Institutional Ethical clearance was taken before performing the study. All pregnant and postpartum women who had presented with fever or acute respiratory illness were included in the study and subsequently were tested for H1N1 by a pharyngeal swab from March 2017 to Feb 2019. In the present study, we included women up to two weeks postpartum because after that risks equal to the general population. ${ }^{9,10}$ A total of 52 cases were included. Laboratory confirmation by RT-PCR and virus isolation was also taken in account.

Maternal age, period of gestation, duration between onset of symptoms and presentation to hospital or initiation of treatment were recorded. Pregnant women, who only had influenza like symptoms without signs of respiratory distress, pathological lung sounds, and infiltrates on a chest radiograph, were managed as outpatient with strict instructions to report if condition deteriorates. On the other hand, women who had fever, non-productive or dry cough, tachypnoea, dyspnoea, wheezing, intercostals retraction, decreased respiratory sounds, hypoxia, acute respiratory distress, and alveolar opacities on a chest radiograph were admitted. The parameters considered for a critical infection were presence of mental confusion, respiratory rate $>30$ breaths/min, diastolic $\mathrm{BP}<60$, systolic $\mathrm{BP}<90 \mathrm{~mm}$ of $\mathrm{Hg}$, fever higher than $38^{\circ} \mathrm{C}$ associated with cough and dyspnoea ${ }^{7}$. Patients were investigated and treated as per the hospital protocol during their course of illness. All these patients were treated by oral Oseltamivir, $75 \mathrm{mg}$ twice daily for five days. The criteria for starting treatment was either empirical or after confirmation by laboratory tests.

Statistical analysis was done using t-test and chi square test. $\mathrm{P}$ value $<0.05$ was considered significant.

\section{Results}

A total of 52 patients in pregnancy and postpartum period were admitted with fever or acute respiratory illness over the period of two years from March 2017 to February 2019.

Table 1: Clinical presentation in H1N1 positive cases

\begin{tabular}{lll}
\hline Clinical presentation & Numbers & Percentage (\%) \\
\hline Fever & 30 & 93.8 \\
Cough & 17 & 53.1 \\
Dyspnoea & 10 & 31.3 \\
Myalgia & 3 & 9.4 \\
Sore throat & 2 & 6.3 \\
Weakness & 4 & 12.5 \\
Chills & 7 & 21.9 \\
Decrease urine output & 2 & 6.3 \\
Edema & 2 & 6.3 \\
Labor pain & 6 & 18.6 \\
Pneumonia & 2 & 6.3 \\
Intubation & 5 & 15.6 \\
ARDS & 4 & 12.5 \\
Pulmonary edema & 2 & 6.3 \\
Hemodynamic instability & 3 & 9.4 \\
Decrease SPO & 7 & 21.9 \\
Altered sensorium & 1 & 3.1 \\
\hline ARDS = Acute respiratory distress syndrome
\end{tabular}

Mean age of patients was 25.88 years. Out of these 52 patients, 32 patients were H1N1 positive and rests of 30 patients were H1N1 negative. In all H1N1 positive cases, 29 were pregnant and 3 patients were postpartum. Trimester wise distribution is given in table 2. Primigravida constituted $14(48.28 \%)$ of total 29 pregnant H1N1 positive women. Mean gestational age at the time of admission was 31 weeks.

Associated co-morbid conditions like hypertensive disorder of pregnancy were present in 3 patients, scrub typhus in 1 patient, cardiac disease in 2 patients and anemia 
in 7 patients. Cough (97.4\%), fever (98\%), fever and cough $(80 \%)$, sore throat, breathlessness was the most common symptoms observed. (Table 1)

Table 2 : Gestational age at delivery and mode of delivery

\begin{tabular}{lll}
\hline $\begin{array}{l}\text { Gestational } \\
\text { age at delivery }\end{array}$ & Number & $\begin{array}{l}\text { Percentage } \\
\mathbf{( \% )}\end{array}$ \\
\hline$<34$ wks & 2 & 15.4 \\
$34-37$ wks & 2 & 15.4 \\
$>37$ wks & 9 & 69.2 \\
\hline Mode of delivery & \\
\hline Vaginal delivery (spontaneous) & 4 & 30.8 \\
Vaginal delivery (induced) & 2 & 15.4 \\
Caesarean section & 7 & 53.8 \\
Maternal mortality & 4 & 12.5 \\
\hline
\end{tabular}

Six patients were admitted in spontaneous labor, while induction was done in 6 patients. There were total 13 patients delivered, in which, 4 were normal vaginal deliveries and 2 were operative vaginal deliveries. There were total 4 preterm deliveries in which two patients had IUD babies, so they were induced and delivered vaginally. One patient was admitted in preterm labor and delivered vaginally an alive baby with apgar 6; 7 at 33 weeks while other had gone for caesarean section due to previous two caesarean in labor at 32 weeks with alive baby of apgar 7 and 8. In 9 term patients, two patients had IUD babies; in which one was delivered vaginaly while for other caesarean was done because patient was in respiratory failure with failed induction. Rest all caesarean were done for obstetrics indications. (Table 2, 3)

There were two twin deliveries; one was preterm vaginal delivery while other had caesarean section due to preterm

Table 3: Neonatal outcome in H1N1 positive cases

\begin{tabular}{lll}
\hline Birth weight (Kg) & Number & Percentage (\%) \\
\hline$<2 \mathrm{Kg}$ & 5 & 33.3 \\
$2-3 \mathrm{Kg}$ & 6 & 40 \\
$>3 \mathrm{Kg}$ & 4 & 26.7 \\
\hline Apgar score & & \\
\hline$>8$ & 5 & 45.5 \\
$5-8$ & 6 & 54.5 \\
$<5$ & 0 & 0 \\
\hline Intrauterine death & 4 & 30.7 \\
\hline
\end{tabular}

labor with previous caesarean section. In 13 delivered patients, there were 5 intrauterine death and 8 babies were alive. (Table 5)

Out of 32 patients, 11 patients were admitted in intensive care unit. There were 4 deaths due to H1N1 illness in the hospital during the study period, in which all patients were in $3^{\text {rd }}$ trimester. (Table 4)

Out of these four deaths, one patient expired undelivered, one patient expired post delivery and two patients expired post caesarean. All of these patients were already in respiratory failure at the time of admission. Maternal and foetal outcome was poor in women who had critical illness and those who were in the late treatment group.

\section{Discussion}

India is ranked $3^{\text {rd }}$ among the most affected countries for cases and deaths of swine flu globally. ${ }^{11}$ The highest number of cases were reported in $2009(27,236)$, followed by 2010 $(20,604)$ and $2012(5,054$ cases). The highest number of swine flu deaths took place in $2011(1,763)$, followed by 2009 (981) and 2012 (405). ${ }^{12}$

In our study, there were total 52 patients in the period of two years who were admitted with the complaint of fever, cough and breathlessness during pregnancy or two weeks postpartum. Sample for H1N1 was sent. In which, 32 patients were $\mathrm{H} 1 \mathrm{~N} 1$ positive. Maximum number of patients were of 21-25 years of age $(56.3 \%)$ and in third trimester (68.8\%). Prabhu ${ }^{13}$ however, found that $90.6 \%$ of $\mathrm{H} 1 \mathrm{~N} 1$ infected pregnant patients in the series were in the age group between 21 and 29 years, $65.6 \%$ were primigravidae, and $87.5 \%$ were diagnosed in the third trimester. The three most common clinical symptoms in our patients were cough, fever, and breathlessness. Shortness of breath, hemoptysis, hypoxia, wheezes, tachypnea, and decreased air entry, chest radiograph with positive findings were found in patients with severe symptoms who required oxygen therapy and intubation with intensive management. Liu L et al. ${ }^{14}$ reported that in a general population, critical cases were associated with severe hypoxemia, multisystem organ failure, and a requirement for mechanical ventilation.

Delayed initiation of antiviral treatment is a high risk factor for development of critical illness ${ }^{15,16}$. The reason for the delay was probably late presentation to health care facility that is significant in our study $(\mathrm{p}<0.05)$. (Table 6) The $\mathrm{CDC}$ recommends immediate antiviral treatment of pregnant women with suspected or confirmed H1N1 influenza, preferably within $48 \mathrm{~h}$ after the onset of symptoms ${ }^{17}$. In a study, patients who received treatment $48 \mathrm{~h}$ or more after the onset of symptoms had a risk of ICU admission or death four times greater than patients who received treatment earlier ${ }^{18}$. Another Study conducted by Pramanick A et al., reported median reporting time of non-survivor pregnant women suffering from influenza as six days as compared to one and 
Table 4: Clinical details of H1N1 positive patients admitted in intensive care unit (ICU)

\begin{tabular}{|c|c|c|c|c|c|c|}
\hline Gravida & $\begin{array}{l}\text { Gestational } \\
\text { age }\end{array}$ & Co-morbidity & $\begin{array}{l}\text { Interval } \\
\text { between } \\
\text { onset of } \\
\text { symptoms } \\
\text { and drugs }\end{array}$ & Mode of delivery & $\begin{array}{l}\text { Fetal } \\
\text { outcome }\end{array}$ & $\begin{array}{l}\text { Maternal } \\
\text { outcome }\end{array}$ \\
\hline G1 & 39 wks & Respiratory failure & 3-4 days & $\begin{array}{l}\text { Caesarean section due to } \\
\text { fetal distress }\end{array}$ & Alive & Expired \\
\hline G1 & $29 \mathrm{wks}$ & Severe preeclampsia & $3-4$ days & Induced vaginal delivery & IUD & Discharged \\
\hline G1 & $21 \mathrm{wks}$ & ARDS & 5 days & Undelivered & - & LAMA \\
\hline P1L1 & $\begin{array}{l}\text { Postoperative } \\
\text { day } 2\end{array}$ & Breathlessness & 3 day & - & - & Discharged \\
\hline $\begin{array}{l}\text { G3P1L1 } \\
\text { A1 }\end{array}$ & $31 \mathrm{wks}$ & $\begin{array}{l}\text { Scrub typhus, } \\
\text { Severe PAH, ARDS }\end{array}$ & 7 days & Undelivered & - & Discharged \\
\hline G1 & $28 \mathrm{wks}$ & Respiratory failure & 5 days & Undelivered & IUD & Expired \\
\hline P3L1 & $\begin{array}{l}\text { Postoperative } \\
\text { day } 1\end{array}$ & $\begin{array}{l}\text { Laparotomy for } \\
\text { ruptured uterus }\end{array}$ & $\begin{array}{l}\text { Within } 24 \\
\text { hours }\end{array}$ & - & - & Discharged \\
\hline $\begin{array}{l}\text { G3P1L1 } \\
\text { A1 }\end{array}$ & $32 \mathrm{wks}$ & $\begin{array}{l}\text { Twins with previous } \\
\text { LSCS in labour }\end{array}$ & 4 days & $\begin{array}{l}\text { Caesarean section due to } \\
\text { fetal distress }\end{array}$ & Alive & Discharged \\
\hline G1 & $34 \mathrm{wks}$ & ARDS & 5 days & Induced vaginal delivery & IUD & Expired \\
\hline G1 & 37 wks & ARDS & 5 days & $\begin{array}{l}\text { Caesarean section due to } \\
\text { failed instrumental delivery }\end{array}$ & IUD & Expired \\
\hline G1 & $41 \mathrm{wks}$ & Breathlessness & 7 days & Instrumental delivery & IUD & LAMA \\
\hline
\end{tabular}

G - Gravida, P - Parity, L - Living child, A - Abortion, IUD - Intra uterine death, ARDS - Acute respiratory distress syndrome, LAMA - Left against medical advice

a half days in survivors. ${ }^{19}$ Other factor is lack of vaccination against influenza in pregnant women in our country. Studies from North India revealed less awareness in pregnant women

Table 5: Maternal outcome of H1N1 positive cases

\begin{tabular}{lll}
\hline Maternal outcome & Number & Percentage (\%) \\
\hline Died undelivered & 1 & 3.1 \\
Died after delivery & 3 & 9.4 \\
Discharged undelivered & 15 & 46.9 \\
Discharged after delivery & 10 & 31.3 \\
\hline
\end{tabular}

as well as medical personnel regarding vaccination against respiratory illness and $63 \%$ reduction in rate of laboratory confirmed influenza in immunized pregnant women. ${ }^{21}$

Presence of co-morbid illness is a high risk factor for development of critical illness. Incidence of co-morbid illness as high as 48.4 per cent has been reported ${ }^{16}$. Pregnancy with co-morbidities further adds to worsening of the outcome. In the present study, co-morbidities was present in $37.5 \%$ of $\mathrm{H} 1 \mathrm{~N} 1$ cases. However, small numbers limited the significance of this observation. Other studies have also

Table 6: Comparison of clinical characteristics between noncritical (Group A) and critical cases (Group B)

\begin{tabular}{|c|c|c|c|c|}
\hline \multicolumn{2}{|l|}{ Parameters } & Group $A(N=21)$ & Group $B(N=11)$ & Significance \\
\hline \multicolumn{2}{|c|}{ Maternal age, mean $\pm \mathrm{SD}$ (years) } & $25 \pm 3.4$ & $23 \pm 1.5$ & $\mathrm{P}<0.05$ \\
\hline \multicolumn{2}{|c|}{ Gestational age, mean \pm SD (weeks) } & $29 \pm 9.5$ & $32 \pm 6.08$ & $\mathrm{P}>0.05$ \\
\hline \multirow{4}{*}{$\begin{array}{l}\text { Trimester (Number of } \\
\text { patients) }\end{array}$} & $1^{\text {st }}(n=1)$ & $1(100)^{*}$ & 0 & \\
\hline & $2^{\text {nd }}(n=6)$ & $5(83)$ & $1(17)$ & \\
\hline & $3^{\text {rd }}(n=22)$ & $14(64)$ & $8(36)$ & \\
\hline & Postpartum $(n=3)$ & $1(33)$ & $2(67)$ & \\
\hline \multicolumn{2}{|l|}{ Co-morbid illness $(\mathrm{n}=9)$} & $5(56)$ & $4(44)$ & \\
\hline \multirow[t]{2}{*}{ Presentation to hospital } & $<48$ hours $(14)$ & $13(93)$ & $1(7)$ & $\mathrm{P}<0.05$ \\
\hline & $>48$ hours $(18)$ & $8(44)$ & $10(56)$ & \\
\hline \multirow{2}{*}{$\begin{array}{l}\text { Initiation of antiviral } \\
\text { therapy }\end{array}$} & Early $(n=24)$ & $17(71)$ & $7(29)$ & $\mathrm{P}>0.05$ \\
\hline & Late $(n=8)$ & $4(50)$ & $4(50)$ & \\
\hline \multicolumn{5}{|c|}{ *Values in parentheses are percentages, $\mathrm{P}$ value $<0.05$ is significant } \\
\hline
\end{tabular}


Total $11(34 \%)$ patients were admitted in intensive care unit in the present study and mortality rate was $4(12.5 \%)$. All the expired patients were in third trimester. According to Siston $\mathrm{AM}$ et al. $^{23}$ third-trimester infection was associated with the highest death compared with first and second trimesters. Mortality in present study was similar with other studies from Australia and New Zealand which reported a mortality of $11 \%$ in pregnant and postpartum patients. ${ }^{24}$ Even one study from North India which was performed on Influenza like illness on 266 pregnant women has reported mortality of only $8 \%$ but all the deaths occurred in H1N1 positive patients that too in third trimester. ${ }^{25}$ Another study from Brazil reported no death as all the patients received antiviral therapy and specialized care within 24 hours of symptoms. ${ }^{26}$ In present study, all 4 patients who expired, were already in acute respiratory distress syndrome at the time of admission. Jamieson DJ et al. $^{5}$ mentioned the reporting of six deaths in pregnant women to the CDC. All were in women who had developed pneumonia and subsequent acute respiratory distress syndrome requiring mechanical ventilation. ${ }^{5}$

In present study, maximum number of patients was in third trimester $(68.8 \%)$, in which $15.4 \%$ patients delivered less than 34 weeks, $15.4 \%$ patients delivered between 34-37 weeks while $69.2 \%$ delivered after 37 weeks. The overall prematurity rate of $30.8 \%$ could be caused by H1N1 infection. There were 5 cases of intra-uterine fetal death (IUFD) or stillbirths in our study. Pierce $\mathrm{M}$ et al., ${ }^{27}$ found that perinatal mortality is increased due to an increased rate of stillbirth, increased prematurity, increased rate of NICU admission due to secondary pneumonia. Overall $53.8 \%$ of our patients were delivered by cesarean section mostly emergency obstetric indications. The mode of delivery was dictated by obstetric reasons except one patient who underwent a caesarean section because of severe respiratory compromise and induction failure.

Neuraminidase inhibitors (NI) are likely to reduce mortality in hospitalized patients and are effective at reducing secondary symptomatic influenza transmission. ${ }^{28}$ Because pregnancy is a high rather risk situation, all our patients were given NI, even with the potential significant side effects. The US Centres for Disease Control and Prevention recommend chemoprophylaxis with either Oseltamivir or Zanamivir against H1N1 influenza for people at risk of complications, including pregnant women. ${ }^{29}$ The use of NIs is reassuring to pregnant and lactating women as they aren't associated with adverse outcomes or congenital malformations even with early pregnancy exposures. ${ }^{30,31}$ Although cardiac side effects $(1.8 \%)$ and transient neonatal hypoglycemia in the newborns were reported. ${ }^{32,33}$ we did not encounter such side effects in our newborns. None of our patients had received influenza vaccination prior to or during the current pregnancy. Antenatal influenza vaccination can enhance fetal growth and can reduce preterm birthrate. ${ }^{34,35}$ Maternal influenza immunization is a strategy with substantial benefits for both mothers and infants. ${ }^{36}$ Mark G. Thompson et al. ${ }^{37}$ found that pregnant women vaccinated against flu had a $40 \%$ lower risk for hospitalization if they became ill with the infection compared with unvaccinated pregnant women. We, therefore, would expect a reduction in the preterm birth rate, IUGR and NICU admissions should our patients be vaccinated. This is particularly important in our series since we had a very low threshold for testing suspected cases and early initiation of antiviral therapy.

Early treatment with Oseltamivir is associated with a reduced risk of severe disease. Heba $\mathrm{V}$ et al. ${ }^{38}$ found that initiation of Oseltamivir within 48 hours of symptom onset was associated with fewer complications in patients hospitalized with 2009 influenza A (H1N1). Viasus D et al. ${ }^{39}$ reported that timely Oseltamivir administration has a beneficial effect on outcomes in hospitalized adults with $\mathrm{A}$ (H1N1), even in those who are admitted beyond $48 \mathrm{~h}$ after onset of symptoms. Higuera Iglesias $\mathrm{AL}$ et al. ${ }^{40}$ found that earlier initiation of Oseltamivir therapy, even when initiated more than 48 hours after the onset of symptoms, significantly reduced occurrence and severity of pneumonia and shortened hospitalization in pandemic H1N1 2009. Based on these results, patients affected by future influenza pandemics would benefit from early therapy.

\section{Conclusion}

H1N1 influenza A infection in pregnancy is associated with adverse maternal and perinatal outcomes. Medical and public awareness, low threshold for testing pregnant patients, very early initiation of antiviral therapy and multidisciplinary approach in our series decreased the overall adverse effects of this infection. Close attention should be paid to pregnant women in their second and third trimester of pregnancy and to those with co-morbid illness. This is likely to help reduce the ICU admission rates, associated morbidities and mortalities in this group of women. Safety and efficacy of universal immunization of pregnant women against influenza is an area of research. There should be surveillance for 
seasonal influenza and early antiviral therapy and referral to specialized care for pregnant patients of influenza.

\section{Conflict of interest: None. Disclaimer: Nil.}

\section{References}

1. Dawood FS, Jain S, Finelli L, Shaw MW, Lindstrom S, Garten RJ, et al. Novel Swine-Origin Influenza A (H1N1) Virus Investigation Team, authors. Emergence of a novel swine-origin influenza A (H1N1) virus in humans. N Engl J Med. 2009; 360: 2605-15.

2. Centers for Disease Control and Prevention. Pregnant women and novel influenza A (H1N1): considerations for clinicians [Internet]. 2009 June 30 [Cited 2009 August 24]. Available from: http:// www. cdc.gov/ h1n1flu/clinician_pregnant.htm.

3. Centers for Disease Control and Prevention (CDC). Novel influenza A (H1N1) virus infections in three pregnant women-United States, April-May 2009. MMWR Morb Mortal Wkly Rep. 2009; 58: 497-500.

4. Centers for Disease Control and Prevention. Considerations regarding novel $\mathrm{H} 1 \mathrm{~N} 1 \mathrm{flu}$ virus in obstetric settings. 2009 July 6 [2009 August 24]. Available from: http://www.cdc.gov/h1nl flu/guidance/obstetric.htm.

5. Jamieson DJ, Honein MA, Rasmussen SA, Williams JL, Swerdlow DL, Biggerstaff MS, et al. H1N1 2009 influenza virus infection during pregnancy in the USA. Lancet. 2009; 374(9688): 451-8.

6. Mak TK, Mangtani P, Leese J, Watson JM, Pfeifer D.. Influenza vaccination in pregnancy: current evidence and selected national policies. Lancet Infect Dis. 2008; 8(1): 44-52.

7. Stirrat GM. Pregnancy and immunity. BMJ. 1994; 308:1385-86.

8. Pramanick A, Rathore S, Peter JV, Moorthy M, Lionel J. Pandemic (H1N1) 2009 virus infection during pregnancy in South India. Intl J Gynaecol Obstet. 2011; 113: 32-5.

9. Centers for Disease Control and Prevention. Update Interim Recommendations for Obstetric Health Care Providers Related to Use of Antiviral Medications in the Treatment and Prevention of Influenza for the 20092010 Season. 2009 [Cited 2009 August 24]. Available from: http://www.cdc.gov/h1n1 flu/ pregnancy/ antiviral_messages.htm.
10. Figueiró-Filho EA. Obstetric, clinical, and perinatal implications of H1N1 viral infection during pregnancy. Intl J Gynecol Obstet. 2012; 116: 214-8.

11. Sinha NK, Ray A, Das B, Das S, Basak S. Evolutionary complexities of swine flu H1N1 gene sequences of 2009. Biochem Biophys Res Commun. 2009; 390: 349-51.

12. Times of India. 261 swine flu deaths in India in 2013. Available from: http://articles. Times of India. Indiatimes. com/2013- 02-28/india/37351071_1_swineflu-deathshighest-number

13. Prabhu TR. H1N1 influenza virus infection in pregnancy: A study of 32 cases. Journal of SAFOG. 2014; 6(2): 93-7.

14. Liu L, Zhang RF, Lu HZ, Lu SH, Huang Q, Xiong YY, et al. Sixty-two severe and critical patients with 2009 influenza A (H1N1) in Shanghai, China. Chin Med J (Engl). 2011; 124(11):1662-6

15. Royal College of Obstetricians and Gynaecologists (RCOG). Pandemic H1N1 2009 influenza: Clinical management guidelines for pregnancy. London: RCOG; 2009.

16. Figueiró-Filho EA, Oliveira ML, Pompilio MA, Uehara SN, Coelho LR, DeSouza BA, et al. Obstetric, clinical, and perinatal implications of $\mathrm{H} 1 \mathrm{~N} 1$ viral infection during pregnancy. Int J Gynaecol Obstet. 2012; 116: 214-8.

17. Centers for Disease Control and Prevention. Recommendations for early empiric antiviral treatment in persons with suspected influenza who are at increased risk of developing severe disease. Atlanta: CDC; 2009.

18. Siston AM, Rasmussen SA, Honein MA, Fry AM, Seib K, Callaghan WM, et al. Pandemic 2009 influenza A (H1N1) virus illness among pregnant women in the United States. JAMA. 2010; 303:1517-25.

19. Pramanick A, Rathore S, Peter JV, Moorthy M, Lionel J. Pandemic (H1N1) 2009 virus infection during pregnancy in South India. Intl J Gynaecol Obstet. 2011; 113(1): 32-5.

20. Koul PA, Bali NK, Ali S, Jabeen F, Ahmad A, Bhat MA. et al. Poor uptake of influenza vaccination in pregnancy in northern India. Int $\mathbf{J}$ Gynaecol Obstet. 2014; 127(3): 234-7. 
21. Zaman K, Roy E, Arifeen SE, Rahman M, Raqib R, Wilson E, et al. Effectiveness of maternal influenza immunization in mothers and infants. $\mathrm{N}$ Engl $\mathrm{J}$ Med. 2008; 359(15): 1555-64.

22. Jain S, Kamimoto L, Bramley AM, Schmitz AM, Benoit SR, Louie J, et al. Hospitalized patients with 2009 H1N1 influenza in the United States, April-June 2009. N Engl J Med. 2009; 361(200: 1935-44.

23. Siston AM, Rasmussen SA, Honein MA, Fry AM, Seib K, Callaghan WM, et al. Pandemic 2009 influenza A (H1N1) virus illness among pregnant women in the United States. JAMA. 2010; 303(15):1517-27.

24. ANZIC Influenza Investigators and Australasian Maternity Outcomes Surveillance System. Critical illness due to $2009 \mathrm{~A} / \mathrm{H} 1 \mathrm{~N} 1$ influenza in pregnant and postpartum women: population based cohort study. BMJ. 2010; 340: c127.

25. Koul PA, Bali NK, Mir H, Jabeen F, Ahmad A. Influenza Illness in Pregnant Indian Women: A CrossSectional Study. Infect Dis Obstet Gynecol. 2016; 2016: 1248470.

26. Jiménez MF, Beitune PE, Salcedo MP, Ameln AV, Mastalir FP, Bravn LD. Outcomes for pregnant women infected with the influenza A (H1N1) virus during the 2009 pandemic in Porto Alegre, Brazil. Int J Gynaecol Obstet. 2010; 111: 217-9.

27. Pierce M, Kurinczuk JJ, Spark P, Brocklehurst P, Knight M. Perinatal outcomes after maternal 2009/H1N1 infection: national cohort study. BMJ 2011; 14: 342: d3214.

28. Doll Mk, Winters N, Boikos C, Kraicer-Melamed H, Gore G, Quach C. Safety and effectiveness of neuraminidase inhibitors for influenza treatment, prophylaxis, and outlook control: a systematic review of systematic reviews and/or meta-analysis. J Antimicrob Chemother. 2017; 72(11): 2990-3007.

29. Centres for Disease Control and Prevention. What pregnant women should know about H1N1 (formerly called swine flu) virus. Atlanta: CDC; 2009.

30. Graner S, Svensson T, Damase-Michel C, Engeland A, Furu K, Hviid A, et al. Neuraminidase inhibitors during pregnancy and risk of adverse neonatal outcomes and congenital malformations: Population based European register study. BMJ. 2017; 356: j629.
31. Tanaka T, Nakajima K, Murashima A, GarciaBournissen F, Koren G, Ito S. Safety of neuraminidase inhibitors against novel influenza $\mathrm{A}(\mathrm{H} 1 \mathrm{~N} 1)$ in pregnant and breastfeeding women. Canadian Medical Association Journal. 2009; 181(1-2):55-8.

32. Ehrenstein V, Kristensen NR, Monz BU, Clinch B, Kenwright A, Sorensen HT. Oseltamivir in pregnancy and birth outcomes. BMC Infect Dis. 2018; 18(1): 519.

33. Svensson T, Granath F, Stephansson O, Kieler H. Birth outcomes among women exposed to neuraminidase inhibitors during pregnancy. Pharmacoepidemiol Drug Saf. 2011; 20(10): 1030-4.

34. Steinhoff MC, Omer SB. A review of fetal and infant protection associated with antenatal influenza immunization. AJOG. 2012; 207(3): S21-S27

35. Steinhoff MC, Omer SB, Roy E, Arifeen SE, Raqib R, Dodd C, et al. Neonatal outcomes after influenza immunization during pregnancy: a randomized controlled trial. Canadian Medical Association Journal. 2012; 184(6): 645-53.

36. Zaman K, Roy E, Arifeen SE, Rahman M, Raqib R, Wilson E, et al. Effectiveness of maternal influenza immunization in mothers and infants. $\mathrm{N}$ Engl $\mathrm{J}$ Med. 2008; 359(15): 1555-64.

37. Thompson MG, Kwong JC, Regan AK, Katz MA, Drews SJ, Azziz-Baumgartner E, et al. Influenza Vaccine Effectiveness in Preventing Influenzaassociated Hospitalizations During Pregnancy: A Multicountry Retrospective Test Negative Design Study, 2010-2016. Clin Infect Dis. 2019; 68(9):1444-53.

38. Hiba V, Chowers M, Levi-Vinograd I, Rubinovitch B, Leibovici L, Paul M. Benefit of early treatment with Oseltamivir in hospitalized patients with documented 2009 influenza A (H1N1): a retrospective cohort study. J Antimicrob Chemother 2011; 66(5):1150-5.

39. Viasus D, Pano-Pardo JR, Pachon J, Riera M, LopezMedrano F, Paveras A. Timing of Osetlamivir administration and outcomes in hospitalized adult patients with pandemic 2009 influenza A (H1N1) virus infection. Chest. 2011; 140(4):1025-32. 
The New Indian Journal of OBGYN. 2020 (July-December); 7(1)

40. Higuera Iglesias AL, Kudo K, Manabe T, Corcho Berdugo AE, Corrales Baeza A, Alfaro Ramos L. Reducing recurrence and severity of pneumonia due to pandemic H1N1 2009 by early oseltamivir administration: a retrospective study in Mexico. PLoS One. 2011; 6(7): e21838.

Namrata Saxena ${ }^{1}$, Prachi Singh ${ }^{2}$, Shweta Jain ${ }^{3}$, Vineeta Gupta ${ }^{4}$, Bhawna Sharma ${ }^{5}$, Kamal S Negi ${ }^{6}$, Narotam Sharma ${ }^{7}$, Yashika Pehal ${ }^{8}$
${ }^{1}$ Associate Professor; ${ }^{2}$ Assistant Professor; ${ }^{3}$ Assistant Professor; ${ }^{4}$ Professor and Head of the Department;

${ }^{5}$ Associate Professor; ${ }^{8}$ Junior Resident, Department of Obstetrics and Gynaecology, Shri Guru Ram Rai Institute of Medical and Health science, Dehradun, Uttarakhand; ${ }^{6}$ Professor, department of Community Medicine, Shri Guru Ram Rai Institute of Medical and Health science, Dehradun, Uttarakhand; ${ }^{7}$ Scientist and in charge, Swine Flue (H1N1) Laboratories, Biochemistry Department, Shri Guru Ram Rai Institute of Medical and Health science, Dehradun, Uttarakhand, India. 